\title{
The dual myths of the healthy wild fish and the unhealthy farmed fish
}

\author{
Øivind Bergh ${ }^{1,2, *}$ \\ ${ }^{1}$ Institute of Marine Research, PO Box 1870, Nordnes 5817 Bergen, Norway \\ ${ }^{2}$ University of Bergen, Department of Biology, PO Box 7800, 5020 Bergen, Norway
}

\begin{abstract}
Although diseases, suffering and death have always been recognized as intrinsic parts of life as far as humans are concerned, it seems that many people tend to disregard these factors when it comes to animals. In particular, wild fish are generally assumed to be 'healthy', although the public concept of that term is unclear. In contrast, farmed fish are often popularly viewed as 'unhealthy'. Present knowledge of the importance of epizootics among wild fish is clearly limited, especially regarding viral and bacterial diseases. In contrast to the popular view, the available data indicates that disease among wild fish is common, that epizootics may be of significant ecological importance, and that there is reason to believe that fish diseases among wild as well as cultured fish may be associated with reduced welfare. Large-scale aquaculture without prophylaxis is practically impossible without an unacceptable impact on the environment, as well as reduced fish welfare. In this essay, I oppose the traditional view that industrialisation of aquaculture is linked to reduced fish welfare. In contrast, modern industrial aquaculture with state-of-the-art prophylaxis probably represents a major improvement in controlling fish diseases, thus increasing fish welfare. This is true especially when compared to traditional third world aquaculture, as measured in terms of fish mortality and consumption of antibacterial agents. However, aquaculture may influence diseases of wild fish populations either by providing vectors for transmission of pathogens into new geographic areas, or by altering the balance in host-parasite dynamics by increasing the number of available hosts.
\end{abstract}

KEY WORDS: Diseases $\cdot$ Welfare $\cdot$ Treatment $\cdot$ Prophylaxis $\cdot$ Aquaculture $\cdot$ Wild fish

\section{INTRODUCTION}

There is every reason to believe that parasitic life strategies and diseases have been abundant throughout the history of life on Earth. What might be the earliest reliable description of a disease caused by a wild fish, and also a zoonosis, was given by Hippocrates in the fifth century BC. He described a fatal illness in a man who lived on an island in the Aegean Sea. The acute infection was characterized by black bullous skin lesions, rapidly progressive septicaemia, and death on the second day. Today it seems probable that this disease was caused by Vibrio vulnificus and that the man became infected while skinning fish (cf. Baethge \& West 1988).

Today, diseases are generally viewed by science as an integral part of the existence of all animals and plants, including both cultured and wild populations. Man is clearly no exception, and neither are fish. Parasitic organisms naturally exist in an unstable equilibrium with their hosts. This equilibrium is affected by environmental changes and anthropogenic activities, such as for instance the development of aquaculture (cf. Reno 1998). The highly dynamic, unstable nature of this 'equilibrium' may mean that terms like 'equilibrium' are insufficient descriptors, at least in the perception of the general public. There could be no 'ideal' natural state for the relationship between host and pathogen, as the somewhat misleading terms 'equilibrium' or 'natural balance' indicate.

Generally, knowledge of diseases in wild fish has only been generated based on atypical events, such as epizootics in which large numbers of fish were affected, or when observations were made on a limited number 
of fish with no knowledge of the spatial or geographic distribution of the condition. Limited research has been undertaken on diseases of wild fish at the population level, and on the interactions between wild and farmed populations in terms of exchange of pathogens, with a few exceptions, for instance sea lice. This is at least partly due to the tremendous difficulties associated with the study of diseases in wild fish populations: infected fish often die and disappear before they can be detected. Despite the general low level of public and scientific interest in fish health and diseases that existed prior to the advances made in modern aquaculture, a significant amount of information was generated by a few pioneers, see for instance the reviews by Egidius (1987b) on vibriosis, and the review by Hiney \& Olivier (1999) on furunculosis, and references cited therein. It is well documented that vibriosis and furunculosis were commonly occurring in wild fish populations in North European waters prior to the development of modern aquaculture.

Disease is a component of the overall welfare of fish. In my view, this should apply to wild as well as cultured animals. The public and scientific debate often oversimplifies the concept of welfare in aquaculture by neglecting the obvious reference to the state and condition of wild fish. A common argument would be that cultured fish are captive, presumably against their own will, and we are therefore morally bound to treat them differently from wild fish. However, a reference 'gold standard' where no diseases are present should be viewed as mythical only. Certainly, such a reference would be highly different from the situation of wild animals (or humans) in the real world.Nonetheless, it is my impression that such a myth-based disease-free 'standard' has gained considerable public acceptance, at least in the general European and American public opinion. If this is correct, the aquaculture industry would face the impossible task of completely eradicating all diseases in order to be publicly accepted. As no food production - aquatic or terrestrial — has yet been developed in which diseases are totally absent, this prospect would not be a promising one. Thus, it is my opinion that the reference standard of aquaculture in terms of fish welfare, including fish health, should be the status of wild fish and not that of any mythological disease-free creature.

In this essay, I will compare the health of wild and cultured fish, and assess the impact of aquaculture on the health - and thereby partly the overall welfare of wild and cultured fish. The limited amount of reliable quantitative data from wild fish populations requires that the approach taken is descriptive. Examples will primarily be drawn from Norwegian and North European cultivation of Atlantic salmon Salmo salar and other cold-water species.

\section{MYTH 1. LINKS BETWEEN AQUACULTURE AND DISEASE}

Why is there, in the view of the public, a link between aquaculture and fish disease? One reason is that if it were not for the aquaculture industry, very few people would take notice of fish diseases. Domestication of organisms unavoidably also involves 'domestication' of their pathogens. In this process, 'new' diseases are discovered, as aquaculture personnel and scientists are able to access individual fish that would otherwise have died and disappeared. Just as important, fish diseases in aquaculture may often have an economic impact, and thus attract the attention of journalists or investors. Clearly, traditional fisheries may be significantly affected by fish diseases. However, this may often take place without fishermen or anyone else noticing, except for the fact that affected fish populations may decline, which may have a wide range of causes. In contrast, the socio-economic impact of diseases on aquaculture is far more straightforward, and thus easily understood by laymen. As a result, in the view of the general public, fish diseases are generally coupled with cultured fish and viewed as a result of aquaculture.

When species are domesticated, not only new diseases are discovered. Well-known diseases may be well controlled in species where rearing methods, prophylaxis, and other culture practices have been properly developed. However, they are often not equally well controlled in 'new' hosts. For instance, vibriosis caused by Listonella anguillarum (formerly Vibrio anguillarum), which is no longer a significant problem in Norwegian salmonid aquaculture (reviewed by Lillehaug et al. 2003 and Sommerset et al. 2005), is still frequently causing problems for 'new' species in aquaculture, such as halibut (reviewed by Bergh et al. 2001) and cod (reviewed by Bricknell et al. 2006 and Samuelsen et al. 2006). Good prophylaxis (in this case vaccination) in salmonid aquaculture leads us to hope that this disease can be controlled in other species as well. However, in order to provide good protection, it is essential that vaccines, vaccination strategies and other prophylactic approaches are tailored to each domesticated species (Vadstein et al. 2004, Sommerset et al. 2005). For instance, there is evidence of the accumulation of $L$. anguillarum in live feed organisms (Korsnes et al. 2006). Thus, early life stages of fish, which cannot be vaccinated, are particularly susceptible to L. anguillarum and other opportunists (reviewed by Vadstein et al. 2004). This problem is less significant in salmonid aquaculture, partly due to the fact that the early life stages are reared in freshwater, while most of the pathogens are marine.

Artificially high host densities associated with aquaculture is evolutionarily beneficial for pathogens. Duo- 
and polyculture strategies, as often found in traditional and third world aquaculture, will in theory favour transmission of pathogens among hosts (Korsnes et al. $2003,2005)$. This is due to the simultaneous presence of artificially high densities of 2 or more hosts causing a greatly increased number of intra-species contacts, thereby increasing the potential of intra-species transfer. Thus, such culture strategies should not be recommended. Monoculture strategies with adequate prophylaxis do not enhance inter-species transfer of disease.

\section{MYTH 2. THE TROJAN HORSES OF AQUACUL- TURE: INTRODUCED PATHOGENS}

It is generally believed that the greatest risk to both farmed and wild stocks is incurred by the introduction of exotic pathogens into areas where local stocks have no innate resistance. National and international legislative controls are in existence to reduce this risk, but these have not afforded total protection (Mortensen et al. 2006). In the case of salmonids in Norway, which may be among the best-studied examples of interactions beween wild and cultured fish, 2 serious epizootics have occurred as the result of introductions: furunculosis, and infestations by Gyrodactylus salaris (McVicar 1998).

Although several species in the genus Gyrodactylus are known from salmonids, only G. salaris is considered a significant problem for Atlantic salmon. This monogean parasite, which is endemic to Baltic salmon, to which it causes little harm, was imported from Sweden to a Norwegian hatchery at Sunndalsøra in Møre og Romsdal county, where salmon was produced for restocking rivers following hydroelectric power regulations. The disease has since been transferred to salmon rivers, mainly by fishermen. It is still translocated by this vector despite having been eradicated from hatcheries for more than a decade. The Norwegian policy has been eradication of the parasite from Norwegian rivers. At present, the parasite is present in 19 rivers, confirmed to have been eradicated (by rotenone treatment) from another 15, whereas the result of the eradication from another 11 rivers has not been confirmed (Mo \& Norheim 2005). The parasite is unable to survive for long in seawater (Soleng \& Bakke 1997), thus spreading of the parasite via wild salmon is believed to be of minor importance, except in the case of geographically close rivers.

The Gyrodactylus salaris epizootic is a classical example of the consequences of an introduction of a seemingly harmless parasite to native host populations. Although a hatchery, by definition an aquaculture facility, was involved in the introduction, restock- ing of rivers was the motivation for the activities leading to the introduction, and anglers are probably the major vector of transmission to new rivers. Thus, it seems unfair to blame the aquaculture industry for this epizootic, which probably would have occurred even without the existence of that industry.

Furunculosis is a 'classical' fish disease, caused by the Gram-negative bacterium Aeromonas salmonicida subspecies salmonicida. A. salmonicida has been recognized as a pathogen of fish for over $100 \mathrm{yr}$. Emmerich \& Weibel (1894) made the first authentic report of its isolation during a disease outbreak at a Bavarian hatchery (cf. Hiney \& Olivier 1999). The original epizootic spread of furunculosis in both Europe and America and particularly in the British Isles is strongly suggestive of an introduced pathogen (Bakke \& Harris 1998), although today the distribution is nearly global. Furunculosis was first found in Norway in 1964 following the importation of rainbow trout from Denmark. The disease was spread to several farms and to wild fish in the river Numedalslågen. In 1985 furunculosis was discovered in Norwegian marine salmon farms which had received infected salmon smolts imports from Scotland (Egidius 1987a, Johnsen \& Jensen 1994). Rapid spread of the disease was associated with several factors including escapees and natural movement of wild fish in the sea (Johnsen \& Jensen 1994). This resulted in a major epizootic that culminated in the years 1990 to 1992 (Lillehaug et al. 2003), after which the emergence of oil-based adjuvant vaccines more or less eliminated the problem in farmed salmon (reviewed by Sommerset et al. 2005). The ecological consequences are not known, but it should be emphasized that the effective elimination of the problem in aquaculture most likely resulted in a dramatically reduced infection pressure on wild salmon. The disease is not considered a major problem for wild salmon in Norway today, but outbreaks in salmon rivers with low water flow are occasionally registered - with no known connection to aquaculture.

Although it may be wrong to blame the aquaculture industry of today for these diseases, it should be noted that transport of animals seems more difficult to regulate in the European legislative area than other culture practices. The introduction of Gyrodactylus salaris and furunculosis to Norwegian waters shows the potential negative effects of such movements. The risk of pathogen transmission cannot be avoided, but to some extent the level of risk can be subject to political choice. Few aquatic animal diseases have been modelled thoroughly enough to enable a credible risk assessment to be carried out, and few aquaculture management models can reliably ensure that satisfactory health status is maintained in farmed fish or shellfish stocks. Long-distance movement of aquaculture 
organisms is still common. Thus, despite a long history of aquatic animal diseases, European aquaculture still accepts a relatively high level of risk. The mismatch between available knowledge, the level of precautions taken and the risk of financial losses due to disease is mainly due to the principle of free trade and the problem of defining an acceptable level of restriction (Mortensen et al. 2006).

\section{MYTH 3. IMPACTS OF INCREASED HOST ABUNDANCE}

Apart from the introduction of pathogens to new geographic areas, the often artificially high host densities in aquaculture compared to nature may alter host-parasite relationships already established in nature by increasing the number of hosts. Clearly, there are cases where increased host abundance may have had an impact on fish health and welfare. The salmon lice Lepeoptheirus salmonis epizootic is a very different case from that of Gyrodactylus salaris and may be a good example of this. This parasite persisted in Norwegian water along with its host long before the development of the aquaculture industry. However, the increase in host biomass reared in net-pens has severely changed the balance in the host-parasite dynamics. The total number of wild hosts along the Norwegian coast has been estimated at 2 to 2.5 million fish, whereas the standing stock of farmed Atlantic salmon and rainbow trout Onchorhynchus mykiss was 231 million fish by the end of 2002 (Heuch et al. 2005) Thus, hosts are now about a hundred times more abundant than prior to modern salmonid farming. The time from hatching to the first copepodits is long, for instance, $43 \mathrm{~d}$ at $4^{\circ} \mathrm{C}$ (Boxaspen \& Næss 2000). Thus, the potential for salmon lice to spread is large. Even though modern oral delousing drugs are efficient, the challenge pressure on unprotected wild salmonids has increased, with probably huge impacts on wild salmon populations, as well as the welfare of the wild salmon. Major primary and secondary physiological effects, including high levels of plasma cortisol and glucose, reduced osmoregulatory ability, and reduced nonspecific immunity in the host, occur when the lice develop from the sessile chalimus 4 stage to the mobile first preadult stage. Sublethal tertiary effects, such as reduced growth, reduced swimming performance, and impaired immune defense, have also been reported (reviewed by Heuch et al. 2004).

Good prophylaxis is also presently available in the cases of Gram-negative septicaemias such as vibriosis and furunculosis, and these diseases hardly constitute a significant problem in aquaculture. These diseases have been known for a long time, and there is consid- erable documentation of outbreaks in wild populations. The artificially high host density in aquaculture gave the bacteria an advantage in the years prior to the development of efficient vaccines (reviewed by Sommerset et al. 2005)

A typical example of this is Listonella (formerly Vibrio) anguillarum, which has long been known as the causative agent of disease (classical vibriosis). It regularly causes epizootics in wild and cultured populations of several fish species (Egidius 1987b, and articles cited therein), with the oldest known descriptions of the disease dating from 1817. Vibriosis is known in a wide range of fish species. Contact between fish seems to be an important factor for the spread of the pathogen; however, the bacterium is widely distributed in wild fish as well as food organisms and is transmitted horizontally. It caused significant problems for salmonid farming before the advent of modern vaccines. Similarly, Vibrio salmonicida, although originally described from cultured fish (Egidius et al. 1986), caused a major epizooitic of cold-water vibriosis, the so-called 'Hitra disease', during the late 1980s, but it is now completely controlled by vaccines (reviewed by Lillehaug et al. 2003, Sommerset et al. 2005). Thus, like furunculosis, these diseases are well controlled in aquaculture, and good rearing methods and vaccinations have compensated for the negative impacts of artificially high host abundance. However, there are examples of diseases which are not so well controlled by vaccines. For instance, in recent years, 'winter ulcer' has been the most important bacterial disease in Norwegian salmon aquaculture from an economic and fish welfare viewpoint. Moritella viscosa (formerly Vibrio viscosus) is the primary cause of the disease (Lunder et al. 2000); however, other bacteria may also be involved. The disease causes major ulcerations, which likely affect fish welfare. The effect of vaccination has so far been considered inconsistent, and antibacterial treatment may have little or no effect (Coyne et al. 2004, 2006). There is no indication that host density as such influences the development of winter ulcer; however, suboptimal rearing conditions and the general condition of the fish may contribute. It is probable that improved vaccines and improved rearing protocols may control the disease.

When new species are domesticated, at least some attempt should be made to assess the distribution and importance of at least some pathogens of these species which were present in the wild populations at the early stages of industrial development. The artificially high density of hosts in aquaculture may provide improved conditions for parasites. Although proliferation of pathogens, such as sea lice in fish farms, may affect wild fish adversely, the prophylactic approaches applied against sea lice, furunculosis and vibriosis 
have reduced the impact of these diseases to an artificially low level in the case of cultured fish. The question of whether or not this level of impact is sufficiently low such that negative effects on the wild fish populations can be avoided is open to discussion. In the case of salmonids, the high number of cultured salmon relative to wild salmon implies that even small amounts of pathogens released may have a negative impact on the wild salmon. To some extent, the level of environmental impact that can be accepted is a political decision, as in any other industry.

\section{CAN PROPHYLAXIS REPLACE TREATMENT?}

Industrialised aquaculture is dependent on modern prophylactic strategies, particularly vaccines (Sommerset et al. 2005). The large reduction in the consumption of antibacterial agents by the Norwegian aquaculture industry is strongly linked to the development and systematic application of modern fish vaccines by the entire salmon industry (Lillehaug et al. 2003). However, the discovery of gross and histopathological lesions in farmed salmon immunized with oiladjuvanted vaccines has led to increased interest in vaccine side effects. Granulomatous inflammation and melanin accumulation are side effects of the use of oil adjuvants (Koppang et al. 2005). In severe cases, lesions consisting of granulomatous tissue adhering to and embedding different visceral organs can occur in such a way that normal functions may become affected (Poppe \& Breck 1997). Increased focus on vaccination protocols and formulations has greatly reduced the problems (Berg et al. 2006), but to some extent, adverse effects of vaccination still remain a welfare problem in salmon aquaculture. As in human medicine, it is essential to keep the vaccines efficient while reducing their side effects.

Therapy, on the other hand, has severe environmental side effects, at least on a global scale (Cabello et al. 2006). The consumption of antibacterial agents in Norwegian aquaculture reached $50 \mathrm{t} \mathrm{yr}^{-1}$ in 1987, about the same amount used in human medicine in the country. The impact on the environment, and the risk of producing resistance to antibacterial agents, is well documented (Lillehaug et al. 2003 and references cited therein). Today, the consumption of antibacterial agents in Norwegian aquaculture is about $1.2 \mathrm{t} \mathrm{yr}^{-1}$, about $20 \%$ of the total consumption by animals or about 2 to $3 \%$ of the amount consumed per annum in human medicine in the country, which could hardly be viewed as a major environmental problem.

From a strict animal welfare point of view, it could be argued that the consumption of antibiotics is too low. Norwegian animal welfare legislation states that 'ani- mals should not be subject to non-necessary suffering' (Anonymous 1974). It is well established as a legislative practice that captive animals, when suffering from diseases assumed to have a high impact on welfare, should be either treated or killed, even when there is no risk that the disease will be transmitted. Thus, there is a fundamental conflict of interest between the concern for the environment and the concern for animal welfare. This conflict is hardly recognised by environmental or animal welfare non-governmental organisations (NGOs), industry or even public authorities. I suggest that the public debates on the environmental impact of aquaculture, and animal welfare, would benefit from the recognition that these conflicts exist. An interesting ethical problem would be the consumption of antibiotics by pet animals, which in Norway is higher than the consumption by the aquaculture industry. If antibiotics should be banned from the aquaculture industry for environmental reasons, should the ban include the administration of antibiotics to pet animals? The question may be worth asking, at least in order to elucidate the conflict of interests between animal welfare and the wish to minimize the environmental impact of animal husbandry.

\section{CONCLUSION}

Disease is a part of the lives of wild fish and of farmed fish. However, aquaculture activities may alter the geographic distribution of diseases, or alter the host-parasite balance to the benefit of the parasite. Thus, there are links between aquaculture and fish diseases. Often it is not cultured fish that are most susceptible, due to efficient prophylactic strategies and good culture practices. Unprotected wild fish, as exemplified in the case of salmon lice, will be more susceptible to infections and mortality.

As with every human activity, aquaculture is associated with environmental and ethical side effects that may be unwanted by the general public. The side effects and risks cannot be completely eliminated; instead we should actively choose the level of impact on animal welfare and impact on the environment that we are willing to accept. These definitions of acceptable impacts should be viewed as strictly political processes, although the quality of their outcome may benefit from scientific input. For instance, the side effects of prophylaxis should be minimized, but must also be weighed against the environmental impact of disease outbreaks, or of therapeutic countermeasures. In this balancing act, knowledge of the side effects of prophylaxis and the environmental impacts of disease outbreaks and their treatment is a prerequisite for successful management. Thus, development and re- 
finement of methods to minimize the side effects of prophylaxis and environmental impacts of disease outbreaks and treatment will be increasingly important tasks.

The ultimate goal of aquaculture could not, and thus should not, be a mythical disease-free cultured animal, but rather an animal for which the impact of diseases and general level of welfare is acceptable, at least when compared to wild individuals of the same species - an animal belonging in the real world.

\section{LITERATURE CITED}

Anonymous (1974) Lov om dyrevern (Norwegian Animal Protection Act), §2. Norwegian Ministry of Agriculture and Food, Oslo (in Norwegian)

Baethge BA, West BC (1988) Vibrio vulnificus: Did Hippocrates describe a fatal case? Rev Infect Dis 10(3):614-615

Bakke TA, Harris PD (1998) Diseases and parasites in wild Atlantic salmon (Salmo salar) populations. Can J Fish Aquat Sci 55(Suppl 1):247-266

Berg A, Rødseth OM, Tangerås A, Hansen TJ (2006) Time of vaccination influences development of adhesions, growth and spinal deformities in Atlantic salmon Salmo salar. Dis Aquat Org 69:239-248

Bergh Ø, Nilsen F, Samuelsen OB (2001) Diseases, prophylaxis and treatment of the Atlantic halibut Hippoglossus hippoglossus: a review. Dis Aquat Org 48:57-74

Boxaspen K, Næss T (2000) Development of eggs and planktonic stages of salmon lice (Lepeophtheirus salmonis) at low temperatures. Contrib Zool 69:51-55

Bricknell IR, Bron JE, Bowden T (2006) Diseases of gadoid fish in cultivation: a review. ICES J Mar Sci 63(2):253-266

Cabello FC (2006) Heavy use of prophylactic antibiotics in aquaculture: a growing problem for human and animal health and for the environment. Environ Microbiol 8(7): $1137-1144$

Coyne R, Bergh Ø, Samuelsen O, Andersen K, Lunestad BT, Nilsen H, Dalsgaard I, Smith, P (2004) Attempt to validate breakpoint MIC values estimated from pharmacokinetic data obtained during oxolinic acid therapy of winter ulcer disease in Atlantic salmon (Salmo salar). Aquaculture 238: 51-66

Coyne R, Smith P, Dalsgaard I, Nilsen H, Kongshaug H, Bergh $\varnothing$, Samuelsen O (2006) Winter ulcer disease of post-smolt Atlantic salmon: an unsuitable case for treatment? Aquaculture 253:171-178

Egidius E (1986) Vibrio salmonicida sp. nov., a new fish pathogen. Int J Syst Bacteriol 36:518-520

Egidius E (1987a) Import of furunculosis to Norway with Atlantic salmon smolts from Scotland. ICES Mariculture Comm CM1987/F:8

Egidius E (1987b) Vibriosis: pathogenicity and pathology: a review. Aquaculture 67:15-28

Emmerich R, Weibel E (1994) Über eine durch Bakterien erregte Seuche unter der Forellen. Arch Hyg Bakteriol 21: $1-21$

Heuch PA, Bjørn PA, Finstad B, Host JC, Asplin L, Nilsen F (2004) A review of the Norwegian national action plan against salmon lice on salmonids: the effect on wild salmonids. Aquaculture 264(1-4):79-92

Hiney M, Olivier G (1999) Furunculosis (Aeromonas salmonicida) In: Woo PTK, Bruno DW (eds) Fish diseases and disorders, Vol 3. Viral, bacterial and fungal infections. CABI
Publishing, Wallingford, p 341-426

Johnsen BO, Jensen AJ (1994) The spread of furunculosis in salmonids in Norwegian rivers. J Fish Biol 45(1):47-55

Koppang EO, Haugarvoll E, Hordvik I, Aune L, Poppe TT (2005) Vaccine-associated granulomatous inflammation and melanin accumulation in Atlantic salmon, Salmo salar L., white muscle. J Fish Dis 28:13-22

Korsnes K, Nerland A, Mortensen S, Bergh Ø (2003) Interspecies transfer of pathogens caused by polyculture or species introductions - a significant threat to aquaculture? In: Chopin T, Reinertsen H (eds) Beyond monooculture. European Aquaculture Society Special Publication No. 33, Oostende, p 230-231

Korsnes K, Devold M, Nerland AH, Nylund A (2005) Viral encephalopathy and retinopathy (VER) in Atlantic salmon Salmo salar after intraperitoneal challenge with a nodavirus from Atlantic halibut Hippoglossus hippoglossus. Dis Aquat Org 68:7-15

Korsnes K, Nicolaisen O, Skår CK, Nerland AH, Bergh Ø (2006) Bacteria in the gut of juvenile cod Gadus morhua fed live feed enriched with four different commercial diets. ICES J Mar Sci 296-301

Lillehaug A, Lunestad BT, Grave K (2003) Epidemiological description of bacterial diseases in Norwegian aquaculture - a description based on antibiotic prescription data for the ten-year period 1991 to 2000. Dis Aquat Org 53: $115-125$

Lunder T, Sørum H, Holstad G, Steigerwalt AG, Mowinckel P, Brenner DJ (2000) Phenotypic and genotypic characterization of Vibrio viscosus sp. nov. and Vibrio wodanis sp. nov. isolated from Atlantic salmon (Salmo salar) with winter ulcer. Int J Syst Evol Microbiol 50:427-450

McVicar AH (1998) Disease and parasite implications of the coexistence of wild and cultured Atlantic salmon populations. ICES J Mar Sci 54(6):1093- 1103

Mo TA, Norheim K (2005) The surveilance and control programme for Gyrodactylus salaris in Atlantic salmon and rainbow trout in Norway. National Veterinary Institute, Oslo

Mortensen S, Korsnes K, Bergh Ø (2006) 'Eyes wide shut'. A critical view of aquaculture health management and risk factors in the 'real world'. Bull Eur Assoc Fish Pathol 26(1): $1-5$

Peeler EJ, Thrush MA (2004) Qualitative analysis of the risk of introducing Gyrodactylus salaris into the United Kingdom. Dis Aquat Org 62:103-113

Poppe TT, Breck O (1997) Pathology of Atlantic salmon Salmo salar intraperitoneally immunized with oil-adjuvanted vaccine. A case report. Dis Aquat Org 29:219-226

Reno PW (1998) Factors involved in the dissemination of disease in fish populations. J Aquat Anim Health 10:160-171

Samuelsen OB, Nerland AH, Svåsand T, Schrøder M, Jørgensen T, Bergh $\varnothing$ (2006) Viral and bacterial diseases of the Atlantic cod Gadus morhua, their prophylaxis and treatment: a review. Dis Aquat Org 71:239-254

Soleng A, Bakke TA (1997) Salinity tolerance of Gyrodactylus salaris (Platyhelmionthes Monogea): laboratory studies. Can J Fish Aquat Sci 54(8):1837-1864

Sommerset I, Krossøy B, Biering E, Frost P (2005) Vaccines for fish in aquaculture. Expert Rev Vaccines 4(1):89-101

Vadstein O, Mo TA, Bergh Ø (2004) Microbial interactions, prophylaxis and diseases. In: Moksness E, Kjørsvik E, Olsen Y (eds) Culture of cold-water marine fish. Blackwell Scientific Publications, Oxford, p 28-72

Wiklund T, Dalsgaard I (1998) Occurrence and significance of atypical Aeromonas salmonicida in non-salmonid and salmonid fish species: a review. Dis Aquat Org 32:49-69 